\title{
Avaliação agronômica de variedades de cana-de-açúcar inoculadas com bactérias diazotróficas e adubadas com nitrogênio
}

\author{
Nivaldo Schultz ${ }^{(1)}$, Rafael Fiusa de Morais( ${ }^{(1)}$, Jeferson Alves da Silva(1), Rafael Butke Baptista(1), \\ Renan Pedula Oliveira ${ }^{(1)}$, José Marcos Leite(1), Willian Pereira ${ }^{(1)}$, Josil de Barros Carneiro Júnior ${ }^{(1)}$, \\ Bruno José Rodrigues Alves ${ }^{(2)}$, José Ivo Baldani(2), Robert Michael Boddey(2), Segundo Urquiaga ${ }^{(2)}$ \\ e Veronica Massena Reis ${ }^{(2)}$
}

\begin{abstract}
(1)Universidade Federal Rural do Rio de Janeiro, Instituto de Agronomia, Departamento de Ciência do Solo, Rodovia BR 465, Km 7, CEP 23890-000 Seropédica, RJ. E-mail: nsufrrj@yahoo.com.br, rafaelfiusa@yahoo.com.br, jefersonufrrj@yahoo.com.br, rafaelmtb@hotmail.com, renanpedula@agronomo.eng.br, josemarcosleite@yahoo.com.br, willian.pereira@raizen.com, josil@ufrrj.br (2)Embrapa Agrobiologia, BR 465, Km 7, CEP 23890-000 Seropédica, RJ. E-mail: bruno@cnpab.embrapa.br, ibaldani@cnpab.embrapa.br, bob@cnpab.embrapa.br, urquiaga@cnpab.embrapa.br, veronica@cnpab.embrapa.br
\end{abstract}

Resumo - O objetivo deste trabalho foi avaliar a eficiência da inoculação de bactérias diazotróficas e da adubação nitrogenada, em duas variedades de cana-de-açúcar, cultivadas nas mesmas condições edafoclimáticas. O experimento foi conduzido durante os anos agrícolas de 2006/2007 e 2008/2009, em delineamento experimental de blocos ao acaso, com quatro repetições, instalado em março de 2006 em área de cultivo comercial, no Município de Campos dos Goytacazes, RJ. Os tratamentos foram: inoculação com bactérias diazotróficas, adubação com $120 \mathrm{~kg} \mathrm{ha}^{-1}$ de $\mathrm{N}$, e o controle sem inoculação e sem adubação com nitrogênio. As variedades de cana-de-açúcar avaliadas foram RB72454 e RB867515. O inoculante continha estirpes de cinco espécies de bactérias diazotróficas. Foram feitas avaliações quanto à produtividade de colmos frescos, ao acúmulo de matéria seca total, ao $\mathrm{N}$ total da parte aérea e quanto à abundância natural de ${ }^{15} \mathrm{~N}$ do $\mathrm{N}$ disponível no solo e na cana-de-açúcar. As variedades apresentaram comportamentos distintos com os tratamentos, em que a RB867515 foi responsiva e a RB72454 não responsiva à inoculação e à adubação nitrogenada. Na variedade RB867515, o crescimento e o acúmulo de N total na parte aérea das plantas, promovidos pela inoculação, foram similares aos do tratamento com adubação nitrogenada.

Termos para indexação: Saccharum, fixação biológica de nitrogênio, interação planta-bactéria.

\section{Agronomic evaluation of varieties of sugar cane inoculated with diazotrophic bacteria and fertilized with nitrogen}

\begin{abstract}
The objective of this work was to evaluate the efficiency of inoculation with diazotrophic bacteria and nitrogen fertilization, in two varieties of sugarcane grown under the same edaphic and climatic conditions. The experiment was carried out during the agricultural years 2006/2007 and 2008/2009, in a randomized block design with four replicates, installed in March 2006 in an area of commercial cultivation in Campos dos Goytacazes city, in Rio de Janeiro state, Brazil. The treatments were: inoculation with diazotrophic bacteria, fertilization with $120 \mathrm{~kg} \mathrm{ha}^{-1} \mathrm{~N}$, and a control without inoculation and without nitrogen fertilization. The sugarcane varieties evaluated were RB72454 and RB867515. The inoculant was composed of five strains of diazotrophic bacteria. Evaluations were done for fresh stalk yield, total dry matter accumulation, total $\mathrm{N}$ of shoots, and ${ }^{15} \mathrm{~N}$ natural abundance from available $\mathrm{N}$ in the soil and in sugarcane. The varieties performed differently to treatments, in which RB867515 was responsive and RB72454 unresponsive to inoculation and nitrogen fertilization. In the variety RB867515, growth and accumulation of total $\mathrm{N}$ in the shoots, promoted by inoculation, were similar to the ones in the treatment with $\mathrm{N}$ fertilization.
\end{abstract}

Index terms: Saccharum, biological nitrogen fixation, plant-bacteria interaction.

\section{Introdução}

O Brasil é atualmente o maior produtor mundial de cana-de-açúcar, com aproximadamente 9,9 milhões de hectares plantados, produtividade média de $72,6 \mathrm{Mg} \mathrm{ha}^{-1}$ e previsão de produção de 651 milhões de toneladas para a safra 2010/2011 (Instituto Brasileiro de Geografia e Estatística, 2011).
As doses de fertilizante nitrogenado, utilizadas nas áreas de cana-de-açúcar no Brasil, são, em média, de $40 \mathrm{~kg} \mathrm{ha}^{-1}$ de $\mathrm{N}$ na cana-planta e de $80 \mathrm{~kg} \mathrm{ha}^{-1}$ de $\mathrm{N}$ nas soqueiras (Nunes Junior et al., 2005), com baixa eficiência de utilização do $\mathrm{N}$ pelas plantas em condições comerciais (Balasubramanian et al., 2004). Aumentar esta eficiência é um desafio, e a inoculação com bactérias diazotróficas pode ser uma alternativa eficiente. 
Há muitas evidências de que a cana-de-açúcar seja beneficiada pela interação com bactérias diazotróficas (Boddey et al., 2003). As formas pelas quais a associação pode beneficiar o desenvolvimento e a produtividade das plantas são: a fixação biológica de nitrogênio (FBN) (Urquiaga et al., 1992); a produção de hormônios promotores de crescimento, como o ácido indolacético (Suman et al., 2001); a solubilização de fosfatos, (Singh et al., 2007; Shukla et al., 2008); o aumento no teor de carbono orgânico do solo; e o aumento de $\mathrm{N}$ e retenção de nutrientes essenciais na rizosfera (Yadav et al., 2009).

Após experimentação em laboratório e casa de vegetação, cinco estirpes de bactérias diazotróficas foram selecionadas para a formulação do inoculante para cana-de-açúcar (Oliveira et al., 2002, 2003). A inoculação proporcionou significativa contribuição da FBN para a variedade de cana-de-açúcar SP70-1143, em solos de baixa fertilidade, e promoveu produtividades similares às de áreas que receberam fertilizante nitrogenado (Oliveira et al., 2006).

Pesquisas realizadas com a cultura de trigo indicam que a inoculação de bactérias diazotróficas não substitui os fertilizantes nitrogenados, porém promove melhor absorção e utilização do $\mathrm{N}$ disponível no solo (Saubidet et al., 2002; Roesch et al., 2005). Neste sentido, Suman et al. (2008) mostraram que variedades de cana, com maior número de bactérias diazotróficas, não somente apresentaram maior potencial de FBN, porém, quando submetidas à metade da dose recomendada de fertilizante nitrogenado, atingiram níveis de produtividade similares aos de plantas com a dose completa.

O objetivo deste trabalho foi avaliar a eficiência da inoculação com bactérias diazotróficas e da adubação nitrogenada em duas variedades de cana-de-açúcar, cultivadas nas mesmas condições edafoclimáticas, em área de cultivo comercial.

\section{Material e Métodos}

O experimento foi realizado em área de cultivo comercial de cana-de-açúcar, da usina Santa Cruz S.A., em Campos dos Goytacazes, RJ (21 ${ }^{\circ} 45^{\prime} 14$ "S e $41^{\circ} 19^{\prime} 26^{\prime \prime} \mathrm{W}$, a $14 \mathrm{~m}$ de altitude). As avaliações foram realizadas nas safras de 2006/2007, na cana-planta com 18 meses, e 2008/2009, na segunda soca, colhida 12 meses após o corte da primeira soca. O clima da região é do tipo Aw, conforme a classificação de Köppen, com inverno seco e verão quente e chuvoso, e a temperatura média anual é de $22,7^{\circ} \mathrm{C}$. Durante o ciclo de cana-planta, de março de 2006 a julho de 2007, a precipitação acumulada foi de $1.565 \mathrm{~mm}$; no ciclo da primeira soca, de agosto de 2007 a julho de 2008, o total foi de $977 \mathrm{~mm}$, e no ciclo da segunda soca, agosto de 2008 a julho de 2009, de $1.540 \mathrm{~mm}$ (Figura 1).

O solo da área experimental foi classificado como Cambissolo Flúvico eutrófico, conforme Santos et al. (2006), com argila de atividade alta e elevada capacidade de retenção de umidade. Antes da instalação do experimento, realizou-se a amostragem de solo das profundidades de $0-20$ e $20-40 \mathrm{~cm}$, para a caracterização química (Tabela 1).

O solo foi preparado com aração, gradagem e abertura dos sulcos para o plantio, que foi realizado em março de 2006. A adubação foi baseada na análise de solo e na necessidade da cultura, com aplicação ao plantio de $400 \mathrm{~kg} \mathrm{ha}^{-1}$ da formulação 04-30-20, na forma de N, $\mathrm{P}_{2} \mathrm{O}_{5}$ e $\mathrm{K}_{2} \mathrm{O}$. Além da fertilização química, foi aplicado, ao fundo dos sulcos, o equivalente a $15 \mathrm{Mg} \mathrm{ha}^{-1}$ de torta de filtro no momento do plantio. Uma semana após cada colheita, foi efetuada a adubação em cobertura, nas linhas de plantio, e foram aplicados $120 \mathrm{~kg} \mathrm{ha}^{-1} \mathrm{de}$ $\mathrm{K}_{2} \mathrm{O}$, na forma de cloreto de potássio; $80 \mathrm{~kg} \mathrm{ha}^{-1} \mathrm{de}$ $\mathrm{P}_{2} \mathrm{O}_{5}$, na forma de superfosfato simples, $40 \mathrm{~kg} \mathrm{ha}^{-1} \mathrm{de}$ FTE BR12, para o fornecimento de micronutrientes, e $0,4 \mathrm{~kg} \mathrm{ha}^{-1}$ de molibdato de sódio.

As cinco estirpes de bactérias diazotróficas, que compuseram o inoculante para a cana-de-açúcar,

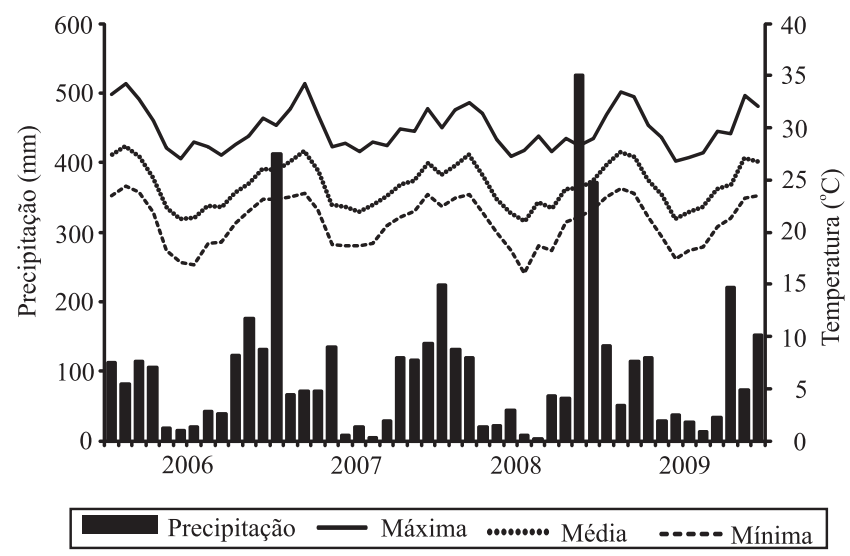

Figura 1. Precipitação e temperatura máxima, média e mínima mensais da região de Campos dos Goytacazes, RJ, no período de condução do experimento (2006 a 2009). 
foram: Pal5 ${ }^{\mathrm{T}}$, de Gluconacetobacter diazotrophicus; Cbamc, de Herbaspirilum seropedicae; HRC54, Herbaspirilum rubrisubalbicans; HCC103, de Azospirilum amazonense; e $\mathrm{PPe} 8^{\mathrm{T}}$,de Bulkholderia tropica. Estas cinco estirpes foram previamente testadas e selecionadas por Oliveira et al. (2003). Para a obtenção do inoculante, as bactérias foram cultivadas em meio de cultura Dyg's (Rodrigues Neto et al., 1986) de forma individualizada. Em seguida, $75 \mathrm{~mL}$ de meio de cultura Dyg's, com população de $10^{9}$ células $\mathrm{mL}^{-1} \mathrm{de}$ cada estirpe, foram adicionados a $175 \mathrm{~g}$ de turfa estéril ( $\mathrm{pH}$ final 6,0), e essa mistura foi acondicionada em saco de plástico de $250 \mathrm{~g}$, para cada estirpe. Por ocasião do plantio, a suspensão inoculante foi preparada por diluição homogênea do conteúdo dos cinco sacos de $250 \mathrm{~g}$ em $100 \mathrm{~L}$ de água limpa.

As mudas utilizadas foram derivadas de plantas micropropagadas. As variedades estudadas foram RB72454 e RB867515. A variedade RB72454 é de baixa exigência quanto à fertilidade de solo, e a variedade RB867515 apresenta alta produtividade em solos de média fertilidade natural. A melhor época de colheita de ambas é do meio ao final da safra (Catálogo nacional de variedades "RB” de cana-de-açúcar, 2010). O preparo das mudas foi realizado na Biofábrica da Universidade Federal Rural do Rio de Janeiro, Campus Leonel Miranda, Campos dos Goytacazes, RJ, da seguinte forma: $1 / 3$ das plantas micropropagadas (100 mudas) foi tratada com o inoculante de bactérias diazotróficas, conforme Reis et al. (1999), comaplicação de $0,1 \mathrm{~mL}$ da suspensão inoculante com $10^{9}$ células por $\mathrm{mL}$ por plântula. Em seguida, todas as plântulas (300 mudas, 100 para cada tratamento de campo) foram transplantadas para canteiros separados por tratamento (tratamento com inoculação, controle sem inoculação e tratamento com adubação de $120 \mathrm{~kg} \mathrm{ha}^{-1}$ de N), em casa de vegetação, onde permaneceram por seis meses à temperatura ambiente, com irrigação monitorada diariamente, para evitar que as plantas fossem submetidas à condição de estresse hídrico. Após esta etapa, as mudas foram transplantadas para o viveiro a pleno sol. Dez meses após o plantio no viveiro, foram retirados os toletes para o plantio do experimento na área comercial da usina.

No momento do plantio em campo, as mudas do tratamento com inoculação da fase de preparação no viveiro passaram por nova inoculação. Após a padronização das mudas em toletes com três gemas, a quantidade de toletes necessária para cada sulco de plantio foi colocada em sacos de ráfia e imersa na suspensão inoculante, preparada por meio da diluição homogênea dos cinco sacos de $250 \mathrm{~g}$ de turfa estéril, que continham as bactérias em $100 \mathrm{~L}$ de água limpa por ocasião do plantio $\left(12,5 \mathrm{~g} \mathrm{~L}^{-1}\right)$. Após a imersão, os toletes foram retirados da solução, mantidos à sombra natural por $30 \mathrm{~min}$ e, em seguida, foram plantados. Para os tratamentos controle absoluto e controle nitrogenado, as mudas também foram padronizadas com três gemas por tolete. Assim, os tratamentos foram: toletes provenientes de plantas micropropagadas sem inoculação (controle); toletes provenientes de plantas micropropagadas, com inoculação no viveiro e no plantio definitivo em campo (com inoculação); e toletes de plantas micropropagadas, adubados com $120 \mathrm{~kg} \mathrm{ha}^{-1}$ de $\mathrm{N}$ fertilizante, na forma de ureia, no momento do plantio em campo.

Utilizou-se o delineamento experimental de blocos ao acaso, em arranjo fatorial $3 \times 2$, constituído de três tratamentos: inoculação, testemunha nitrogenada e controle, em duas variedades, com quatro repetições. As parcelas foram constituídas por quatro linhas de $4 \mathrm{~m}$ de comprimento, espaçadas em 1,40 m, o que totalizou a área útil de $11,2 \mathrm{~m}^{2}$ para cada parcela e duas linhas de bordadura.

Para a uniformidade do estande, definiu-se um número de toletes que permitisse de 12 a 15 gemas por metro de sulco. Para evitar possível contaminação, os tratamentos foram plantados na seguinte ordem: testemunha absoluta; adubação com $120 \mathrm{~kg} \mathrm{ha}^{-1}$ de N; e tratamento com inoculação. A adubação nitrogenada, com uso de ureia, foi dividida em duas parcelas: $50 \%$ da dose aplicada ao fundo do sulco, no plantio; e o

Tabela 1. Atributos químicos do solo, antes do plantio de cana de açúcar ${ }^{(1)}$.

\begin{tabular}{|c|c|c|c|c|c|c|c|c|c|}
\hline \multirow{2}{*}{$\begin{array}{l}\text { Profundidade } \\
\text { (cm) }\end{array}$} & \multirow{2}{*}{$\begin{array}{c}\mathrm{pH} \\
\mathrm{H}_{2} \mathrm{O}\end{array}$} & $\mathrm{C}$ & $\mathrm{N}$ & $\mathrm{Ca}$ & $\mathrm{Mg}$ & $\mathrm{Al}$ & \multirow{2}{*}{$\begin{array}{c}\mathrm{V} \\
(\%)\end{array}$} & $\mathrm{P}$ & K \\
\hline & & \multicolumn{2}{|c|}{----- $\left(\mathrm{g} \mathrm{dm}^{-3}\right)$------ } & \multicolumn{3}{|c|}{------- $\left(\mathrm{cmol}_{\mathrm{c}} \mathrm{dm}^{-3}\right)$-------- } & & \multicolumn{2}{|c|}{----- $\left(\mathrm{mg} \mathrm{dm}^{-3}\right)$----- } \\
\hline $0-20$ & 5,0 & 8,3 & 0,7 & 3,2 & 1,8 & 0,4 & 56,0 & 5,0 & 100,0 \\
\hline $20-40$ & 5,8 & 6,7 & 0,6 & 3,9 & 2,2 & 0,0 & 68,0 & 18,0 & 49,0 \\
\hline
\end{tabular}

${ }^{(1)}$ Fonte: Nogueira \& Souza (2005). 
restante aos 50 dias após o plantio. A adubação foi aplicada à soqueira de uma só vez, em superfície, três dias após a colheita. A suspensão inoculante com bactérias diazotróficas $(12,5 \mathrm{~g}$ de inoculante por litro de suspensão), com diluição igual à utilizada para o plantio, foi aplicada à soca, três dias após a colheita, com utilização de aplicador pulverizador costal, com jato dirigido à base da soqueira, a $14 \mathrm{~mL} \mathrm{~m}^{-1}$ linear de sulco, equivalente à dose de $100 \mathrm{~L} \mathrm{ha}^{-1}$.

As avaliações agronômicas foram realizadas com a determinação da produtividade de colmos, matéria seca total e $\mathrm{N}$ total da parte aérea das plantas (colmos, palha e folhas-bandeira), nas colheitas da cana-planta e da segunda soqueira. Com base na massa de matéria fresca por parcela e na percentagem de matéria seca, foram estimadas a produtividade de colmos frescos e a massa de matéria seca total da parte aérea. Após a pesagem das frações colmos, palha e folhas-bandeira no campo, foram retiradas subamostras, que foram secadas em estufa de circulação forçada de ar a $65^{\circ} \mathrm{C}$ até que atingissem massa constante. As subamostras foram inicialmente passadas em moinho tipo Wiley $(2 \mathrm{~mm})$ para, depois, serem finamente moídas em um sistema similar ao de Arnold \& Schepers (2004). Em seguida, foram realizadas as determinações de $\mathrm{N}$ total segundo método semimicro-Kjeldahl (Nogueira \& Souza, 2005). A análise de abundância natural de ${ }^{15} \mathrm{~N}\left(\delta{ }^{15} \mathrm{~N}\right)$ foi feita somente nas subamostras das folhas-bandeira, que segundo Boddey et al. (2001) representa a marcação isotópica de toda a planta. Após a análise do teor de $\mathrm{N}$ total nas folhas-bandeira, foram determinados os pesos para análise de $\delta^{15} \mathrm{~N}$, dividindo-se o valor 4 pelo teor de $\mathrm{N}$ total em percentual, para atender o espectro de ação do espectrômetro de massas (Finnigan MAT, Bremen, Alemanha) do Laboratório de Isótopos Estáveis John M. Day da Embrapa Agrobiologia (Ramos et al., 2001).

A uniformidade da marcação de ${ }^{15} \mathrm{~N}$ do $\mathrm{N}$ disponível do solo para as plantas, no tempo e em profundidade, é um dos pressupostos para a utilização da técnica de diluição isotópica de ${ }^{15} \mathrm{~N}$, para a quantificação da FBN, desde que as plantas testemunhas tenham enraizamento e marcha de absorção de $\mathrm{N}$ do solo similares aos da planta em avaliação (Unkovich et al., 2008). Para avaliar a FBN, a planta testemunha foi a própria cultura da cana-de-açúcar sem inoculação das bactérias citadas.
Para verificar o grau de uniformidade do isótopo ${ }^{15} \mathrm{~N}$ do $\mathrm{N}$ disponível no perfil do solo, foram coletadas amostras de solo em três pontos dentro de cada parcela, das camadas de 0 a 15, 15 a 30, 30 a 45 e 45 a $60 \mathrm{~cm}$ de profundidade. Essas amostras foram secadas e peneiradas em malha de $2 \mathrm{~mm}$, e uma subamostra foi enviada para o laboratório para análise de $\mathrm{N}$ total do solo (Nogueira, 2005). Estas amostras de solo foram colocadas em vasos de $500 \mathrm{~g}$ de capacidade, em casa de vegetação. Cada camada de solo amostrada foi cultivada por três espécies de plantas testemunhas com quatro repetições. Foi utilizado o delineamento de blocos ao acaso. As plantas testemunhas foram sorgo (Sorghum bicolor), painço (Panicum miliaceum) e milheto (Pennisetum glaucum), consideradas não fixadoras de $\mathrm{N}_{2}$. Antes da semeadura, foi realizada a adubação com $100 \mathrm{mg} \mathrm{kg}^{-1}$ de $\mathrm{P}_{2} \mathrm{O}_{5}$, na forma de superfosfato simples, $100 \mathrm{mg} \mathrm{kg}^{-1}$ de $\mathrm{K}_{2} \mathrm{O}$, na forma de sulfato de potássio, $20 \mathrm{mg} \mathrm{kg}^{-1}$ de sulfato de magnésio, e $50 \mathrm{mg} \mathrm{kg}^{-1}$ de FTE BR12. Após a adubação foi realizada a semeadura, tendo-se utilizado entre 6 e 10 sementes por vaso. Cada vaso recebeu apenas uma espécie. As plantas foram cultivadas por aproximadamente 30 dias, quando começaram a apresentar amarelecimento das folhas, o que indica o esgotamento de $\mathrm{N}$ disponível do solo. Em seguida, as plantas foram coletadas inteiras (raízes e parte aérea) e foram secas, moídas, pulverizadas e analisadas conforme descrito anteriormente para as subamostras de cana-de-açúcar. A uniformidade do isótopo ${ }^{15} \mathrm{~N}$ do $\mathrm{N}$ disponível no perfil do solo foi calculada pela média ponderada do $\mathrm{N}$ extraído pelas plantas testemunhas, por vaso (mg), a cada profundidade, e os respectivos valores de $\delta^{15} \mathrm{~N}$, em que o $\mathrm{N}$ disponível no perfil do solo foi o fator de ponderação.

Os resultados foram submetidos a análises estatísticas, para se verificar a distribuição normal dos dados e a homogeneidade das variâncias pelo programa SAEG; a análise de variância e o teste de médias foram feitos com o Sisvar 4.3, e as médias foram comparadas pelo teste $\mathrm{t}$, a 5 e $10 \%$ de probabilidade.

\section{Resultados e Discussão}

A variedade RB867515 foi responsiva tanto à adubação nitrogenada quanto à inoculação das estirpes bacterianas na segunda soqueira, ao passo que a variedade RB72454 não foi influenciada pelos 
tratamentos nos dois anos avaliados (Tabela 2). As duas variedades apresentaram produtividade elevada no ciclo de cana-planta, com redução acentuada na segunda soqueira. Na média geral, a variedade RB72454 foi superior à variedade RB867515 quanto à produtividade de colmos na cana-planta. Na soqueira, não houve diferença entre as duas variedades quanto às médias gerais avaliadas. A inoculação e a adubação nitrogenada não influenciaram a produtividade de colmos da variedade RB72454, nas duas colheitas avaliadas. Da mesma forma, o acúmulo de matéria seca e $\mathrm{N}$ total da parte aérea das plantas, na variedade RB72454, avaliados na cana-planta e segunda soca, também não foram afetados pelos tratamentos com inoculação e adubação nitrogenada. No entanto, diferenças significativas, quanto à produtividade de colmos, foram observadas na segunda soqueira da variedade RB867515. Na segunda soqueira (2008/2009), as plantas controle apresentaram produção de colmos, massa de matéria seca e teor de $\mathrm{N}$ total significativamente menores do que os dos tratamentos com inoculação e adubação. A elevada produtividade -acima de $150 \mathrm{Mg} \mathrm{ha}^{-1}$-, observada nas duas variedades, na fase de cana-planta, pode ser explicada por alguns fatores inerentes ao ciclo de cana-planta e às condições de implantação e condução do ensaio, com destaque para: preparo e correção do solo; adição de $15 \mathrm{Mg} \mathrm{ha}^{-1}$ de torta de filtro; nutrientes adicionados aos toletes utilizados como mudas; eorigem dasmudas provenientes de plantas micropropagadas, cultivadas em viveiro, com acompanhamento periódico. Outro fator determinante, que explica a alta produtividade na cana-planta, é o regime de chuvas ao longo do ciclo, cuja precipitação foi superior a $100 \mathrm{~mm}$, nos meses de março e abril de 2006, logo após o plantio (Figura 1). A precipitação total $(1.565 \mathrm{~mm})$ e a distribuição das chuvas, ao longo do ciclo de cana-planta, proporcionaram condições adequadas para o desenvolvimento e produtividade da cultura.

A ausência de resposta da variedade RB72454 à inoculação de bactérias diazotróficas e à adubação nitrogenada pode estar relacionada à capacidade desta cultivar de apresentar alta produtividade mesmo em solos de baixa fertilidade natural (Catálogo nacional de variedades "RB" de cana-de-açúcar, 2010). Este fato poderia ser explicado pela associação eficiente que esta variedade apresenta naturalmente com bactérias diazotróficas (Boddey et al., 2001), o que dificulta a associação das bactérias do inoculante com as plantas. A variedade RB867515 é, no entanto, mais exigente quanto à fertilidade de solo (Catálogo nacional de variedades "RB" de cana-de-açúcar, 2010), o que justifica sua resposta ao fertilizante nitrogenado e à inoculação. O genótipo da variedade RB867515 respondeu melhor à inoculação, o que favoreceu o aumento de produtividade em comparação à

Tabela 2. Produtividade de colmos, acúmulo de matéria seca e N total da parte aérea de cana de açúcar, das safras 2006/2007 e 2008/2009, com adubação nitrogenada, inoculação de bactérias diazotróficas e controle sem inoculação ${ }^{(1)}$.

\begin{tabular}{|c|c|c|c|c|c|c|}
\hline \multirow[t]{3}{*}{ Tratamento } & \multicolumn{3}{|c|}{ RB72454 } & \multicolumn{3}{|c|}{ RB867515 } \\
\hline & Produtividade & Matéria seca & \multirow{2}{*}{$\begin{array}{c}\mathrm{N} \text { total } \\
\left(\mathrm{kg} \mathrm{ha}^{-1}\right)\end{array}$} & Produtividade & Matéria seca & \multirow{2}{*}{$\begin{array}{l}\mathrm{N} \text { total } \\
\left(\mathrm{kg} \mathrm{ha}^{-1}\right)\end{array}$} \\
\hline & \multicolumn{2}{|c|}{ 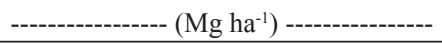 } & & \multicolumn{2}{|c|}{ 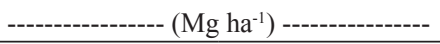 } & \\
\hline & \multicolumn{6}{|c|}{ Cana-planta (2006/2007) } \\
\hline Controle & 172,4 & 69,9 & 242,3 & 137,9 & 61,2 & 156,7 \\
\hline Com inoculação & 153,8 & 65,4 & 179,1 & 152,6 & 74,1 & 234,5 \\
\hline $120 \mathrm{~kg}$ de $\mathrm{N}$ & 177,7 & 72,5 & 238,3 & 157,2 & 69,6 & 224,3 \\
\hline Média & $168,0 \mathrm{~A}$ & 69,2 & 219,9 & $149,4 \mathrm{~B}$ & 68,3 & 205,1 \\
\hline $\mathrm{CV}(\%)$ & 12,8 & 16,2 & 30,9 & 12,8 & 16,2 & 30,9 \\
\hline \multirow[t]{2}{*}{ Teste $\mathrm{t}$} & $*$ & ns & ns & $*$ & ns & ns \\
\hline & \multicolumn{6}{|c|}{ Segunda soqueira $(2008 / 2009)$} \\
\hline Controle & 76,3 & 33,1 & 120,4 & $52,1 \mathrm{~b}$ & $26,2 b$ & $75,5 b$ \\
\hline Com inoculação & 66,3 & 32,0 & 114,6 & $81,4 \mathrm{a}$ & $36,9 \mathrm{a}$ & $132,3 \mathrm{a}$ \\
\hline $120 \mathrm{~kg}$ de $\mathrm{N}$ & 67,5 & 32,1 & 119,2 & $87,5 \mathrm{a}$ & $43,0 \mathrm{a}$ & $165,2 \mathrm{a}$ \\
\hline Média & 67,0 & 32,4 & 118,1 & 73,7 & 35,3 & 124,3 \\
\hline $\mathrm{CV}(\%)$ & 20,5 & 21,1 & 32,9 & 20,5 & 21,2 & 32,9 \\
\hline Teste $\mathrm{t}$ & ns & ns & ns & $*$ & $* *$ & $* *$ \\
\hline
\end{tabular}

${ }^{(1)}$ Médias seguidas de letras iguais, maiúsculas nas linhas e minúsculas nas colunas, não diferem entre si, pelo teste t. ${ }^{\text {ns}}$ Não significativo. $*$ e **Significativo a 5 e $10 \%$ de probabilidade. 
testemunha. Segundo Urquiaga et al. (1992) e Boddey et al. (2003), a interação bactéria-planta e a eficiência da FBN são dependentes do genótipo da planta.

$\mathrm{Na}$ variedade RB72454, os valores de $\delta{ }^{15} \mathrm{~N}$ nas folhas-bandeira das plantas controle e da cana com inoculação foram muito próximos, enquanto na variedade RB867515, o tratamento com inoculação mostrou teores $\delta{ }^{15} \mathrm{~N}$ superiores aos do controle, na fase de cana-planta (Tabela 3). Pela técnica de diluição isotópica de ${ }^{15} \mathrm{~N}$, se a maior produtividade registrada para a variedade RB867515 fosse decorrente do incremento da FBN na planta, deveria ocorrer uma redução proporcional dos valores de $\delta{ }^{15} \mathrm{~N}$ nas plantas com inoculação, em comparação aos das plantas controle (Unkovich et al., 2008). No entanto, há evidências de que os pressupostos de estabilidade e uniformidade de marcação isotópica do solo em profundidade não foram atendidos. Isso pode ser observado pela avaliação do $\mathrm{N}$ disponível e a variabilidade do isótopo ${ }^{15} \mathrm{~N}$, no perfil do solo da área experimental, em que se utilizaram plantas testemunhas cultivadas em vasos, em casa de vegetação (Figura 2). Os resultados mostraram pequena redução do $\mathrm{N}$ disponível e enriquecimento do $\delta{ }^{15} \mathrm{~N}$ em profundidade, onde o valor médio de $\delta{ }^{15} \mathrm{~N}$ das três plantas testemunhas na camada $0-15 \mathrm{~cm}$ foi de $+8,17 \delta{ }^{15} \mathrm{~N}$. Nas camadas 15-30, 30-45 e 45-60 cm, os valores médios foram $+10,56,+9,15$ e $+8,83 \delta{ }^{15} \mathrm{~N}$, respectivamente. Em estudo similar, Urquiaga et al. (2011) verificaram, em um Argissolo Vermelho-Amarelo, redução mais acentuada do $\mathrm{N}$ disponível em profundidade, porém, com enriquecimento do isótopo ${ }^{15} \mathrm{~N}$ em profundidade com o mesmo comportamento observado no presente trabalho. Com a disponibilidade de $\mathrm{N}$ em profundidade, é possível que as plantas que receberam inoculação, mais bem nutridas, tenham apresentado um maior

Tabela 3. Valores de $\delta{ }^{15} \mathrm{~N}$ de folhas bandeira (\%o) de cana de açúcar, das safras de 2006/2007 e 2008/2009, cultivadas em Cambissolo Flúvico, tratadas com inoculação de bactérias diazotróficas e controle sem inoculação ${ }^{(1)}$.

\begin{tabular}{lcccccc}
\hline Tratamento & \multicolumn{2}{c}{ RB72454 } & & \multicolumn{2}{c}{ RB867515 } \\
\cline { 2 - 3 } \cline { 5 - 6 } & Cana-planta & Segunda soca & & Cana-planta & Segunda soca \\
\hline Controle & 7,90 & 5,38 & & $7,13 \mathrm{~b}$ & 5,12 \\
Com inoculação & 8,20 & 4,87 & & $8,90 \mathrm{a}$ & 5,80 \\
\hline CV $(\%)$ & 6,44 & 16,62 & & 6,44 & 16,62 \\
Teste t & ns & ns & & $*$ & ns \\
\hline
\end{tabular}

${ }^{(1)}$ Médias $(n=4)$ seguidas de letras iguais, nas colunas, não diferem pelo

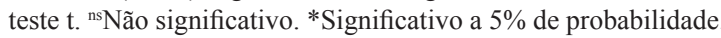

desenvolvimento radicular, que permitiu a absorção de $\mathrm{N}$ de camadas mais profundas do solo com marcação isotópica de ${ }^{15} \mathrm{~N}$ superior ao da camada mais superficial. Essa condição impediria o adequado uso da técnica empregada para quantificar a FBN.

Além disso, o maior vigor, confirmado pelo aumento na produtividade, no acúmulo de matéria seca e $\mathrm{N}$ total na parte aérea das plantas com inoculação, observado na variedade RB867515, também poderia estar associado a outros efeitos promotores de crescimento, além da FBN, como produção de fitormônios (Fuentes-Ramírez et al., 1993; Suman et al., 2001; Bashan et al., 2004), solubilização de fosfatos (Singh et al., 2007; Shukla et al., 2008), aumento no teor de C orgânico do solo, aumento de $\mathrm{N}$ e retenção de nutrientes essenciais na rizosfera (Yadav et al., 2009).

$\mathrm{O}$ efeito promotor de crescimento, o aumento de produtividade de colmos e o acúmulo de matéria seca e $\mathrm{N}$ total na parte aérea, na variedade RB867515, promovidos pela inoculação similar à do tratamento com $\mathrm{N}$ fertilizante, podem estar associados ao aumento de eficiência do sistema radicular em absorver e aproveitar melhor os nutrientes e água em camadas mais profundas do solo. Isto proporciona às soqueiras maior resistência ao estresse hídrico, ocorrido nos dois meses após as colheitas da cana-planta e da primeira soqueira (Figura 1). Segundo Creus et al. (2004), a inoculação de bactérias do gênero Azospirillum, em trigo cultivado em Argissolo, no Instituto Nacional de Tecnologia Agropecuaria na Argentina, aumentou

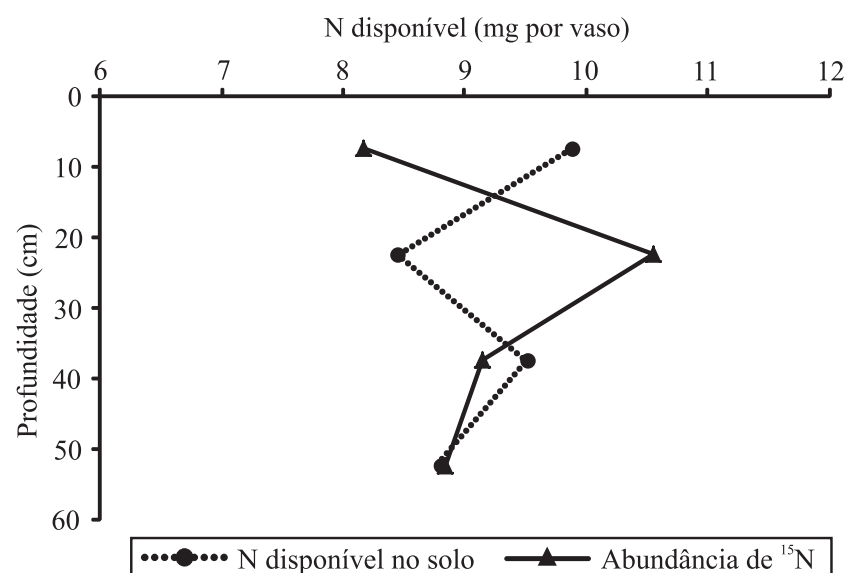

Figura 2. Nitrogênio disponível no perfil de solo, em miligramas por vaso, e variação da abundância de $\delta{ }^{15} \mathrm{~N}(\%)$, extraído pelas plantas testemunhas cultivadas em casa de vegetação: painço (Panicum miliaceum), milheto (Pennisetum glaucum) e sorgo (Sorghum bicolor). 
a resistência das plantas ao estresse hídrico. Oliveira et al. (2006) avaliaram a produtividade das variedades SP70-1143 e SP81-3250, em três solos diferentes - com elevada, média e baixa fertilidade natural - verificaram que o inoculante promoveu aumento significativo na produtividade de colmos somente no solo de baixa fertilidade.

\section{Conclusões}

1. A variedade de cana-de-açúcar RB72454 não apresenta resposta à adubação nitrogenada e à inoculação com bactérias diazotróficas.

2. O inoculante com bactérias diazotróficas promove incremento de desenvolvimento e produtividade similar à adição de $120 \mathrm{~kg} \mathrm{ha}^{-1}$ de $\mathrm{N}$ fertilizante à variedade de cana-de-açúcar RB867515.

\section{Agradecimentos}

Ao Conselho Nacional de Desenvolvimento Científico e Tecnológico e à Fundação Carlos Chagas de Amparo à Pesquisa do Estado do Rio de Janeiro, pelas bolsas concedidas; à Universidade Federal Rural do Rio de Janeiro, ao Campo Experimental Leonel Miranda e à Usina Santa Cruz S.A., pelo apoio na condução da pesquisa; à Embrapa Agrobiologia, pela infraestrutura e orientação científica.

\section{Referências}

ARNOLD, S.L.; SCHEPERS, J.S. A simple roller-mill grinding procedure for plant and soil samples. Commutations in Soil Science and Plant Analysis, v.35, p.537-545, 2004.

BALASUBRAMANIAN, V.; ALVES, B.; AULAKH, M.; BEKUNDA, M.; CAI, Z.; DRINKWATER, L.; MUGENDI, D.; KESSEL, C. van; OENEMA O. Crop, environmental, and management factors affecting nitrogen use efficiency. In: MOSIER, A.R.; SYERS, J.K.; FRENEY, J. (Ed.). Agriculture and the nitrogen cycle. Washington: Scientific Committee on Problems of the Environment, 2004. p.19-33. (SCOPE, 65).

BASHAN, Y.; HOLGUIN, G.; BASHAN, L.E. Azospirillum-plant relationships: physiological, molecular, agricultural and environmental advances (1997-2003). Canadian Journal of Microbiology, v.50, p.521-577, 2004.

BODDEY, R.M.; POLIDORO, J.C.; RESENDE A.S.; ALVES, B.J.R.; URQUIAGA, S. Use of the ${ }^{15} \mathrm{~N}$ natural abundance technique for the quantification of the contribution of $\mathrm{N}_{2}$ fixation to grasses and cereals. Australian Journal of Plant Physiology, v.28, p.889-895, 2001.
BODDEY, R.M.; URQUIAGA, S.; ALVES, B.J.R.; REIS, V.M. Endophytic nitrogen fixation in sugarcane: present knowledge and future applications. Plant and Soil, v.252, p.139-149, 2003.

CATÁLOGO nacional de variedades "RB" de cana-de-açúcar. Curitiba: Rede Interuniversitária para o Desenvolvimento do Setor Sucroalcooleiro, 2010. 136p.

CREUS, C.M.; SUELDO, R.J.; BARASSI, C.A. Water relations and yield in Azospirillum-inoculated wheat exposed to drought in the field. Review Canadian Journal of Botanic, v.2, p.273-281, 2004.

FUENTES-RAMÍREZ, L.E.; JIMÉNEZ-SALGADO, T.; ABARCA-OCAMPO, I.R.; CABALERO-MELLADO, J. Acetobacter diazotrophicus, an indoleacetic producing bacterium isolated from sugarcane cultivars of Mexico. Plant and Soil, v.154, p.145-150, 1993.

INSTITUTO BRASILEIRO DE GEOGRAFIA E ESTATÍSTICA. Levantamento sistemático da produção agrícola, Sistema IBGE e recuperação automática - SIDRA. Disponível em: $<$ www.ibge. gov.br>. Acesso em: 7 dez. 2011.

NOGUEIRA, A.R. de A.; SOUZA, G.B. de. Manual de laboratórios: solo, água, nutrição vegetal, nutrição animal e alimentos. São Carlos: Embrapa Pecuária Sudeste, 2005. 313p.

NUNES JUNIOR, D.; PINTO, R.S.A.; TRENTO, F.E.; ELIAS, A.I. Indicadores agrícolas do setor canavieiro: safra 2003/2004. Ribeirão Preto: Idea, 2005. 111p.

OLIVEIRA, A.L.M. de; CANUTO, E. de L.; REIS, V.M.; BALDANI, J.I. Response of micropropagated sugarcane varieties to inoculation with endophytic diazotrophic bacteria. Brazilian Journal of Microbiology, v.34, p.59-61, 2003.

OLIVEIRA, A.L.M. de; CANUTO, E. de L.; URQUIAGA, S.; REIS, V.M.; BALDANI J.I. Yield of micropropagated sugarcane varieties in different soil types following inoculation with endophytic diazotrophic bacteria. Plant and Soil, v.284, p.23-32, 2006.

OLIVEIRA, A.L.M. de; URQUIAGA, S.; DÖBEREINER, J.; BALDANI, J.I. The effect of inoculating endophytic N2-fixing bacteria on micropropagated sugarcane plants. Plant and Soil, v.242, p.205-215, 2002.

RAMOS, M.G.; VILLATORO, M.A.A.; URQUIAGA, S.; ALVES, B.J.R.; BODDEY, R.M. Quantification of the contribution of biological nitrogen fixation to tropical green manure crops and the residual benefit to a subsequent maize crop using ${ }^{15} \mathrm{~N}$-isotope techniques. Journal of Biotechnology, v.91, p.105-115, 2001.

REIS, V.M.; OLIVARES, F.L.; OLIVEIRA, A.L.M. de; REIS JUNIOR, F.B. dos; BALDANI, J.I.; DÖBEREINER, J. Technical approaches to inoculate micropropagated sugar cane plants with Acetobacter diazotrophicus. Plant and Soil, v.206, p.205-211, 1999.

RODRIGUES NETO, J.; MALAVOLTA, J.R.; VICTOR, O. Meio simples para isolamento e cultivo de Xanthomonas campestris pv. citri tipo B. Suma Phytopathologica, v.12, p.16, 1986.

ROESCH, L.F.; CAMARGO, F. de O.; SELBACH, P.A.; SÁ, E.S. de. Reinoculação de bactérias diazotróficas aumentando o crescimento de plantas de trigo. Ciência Rural, v.35, p.1201-1204, 2005 . 
SANTOS, H.G. dos; JACOMINE, P.K.T.; ANJOS, L.H.C. dos; OLIVEIRA, V.A. de; OLIVEIRA, J.B. de; COELHO, M.R.; LUMBRERAS, J.F.; CUNHA, T.J.F. (Ed.). Sistema brasileiro de classificação de solos. 2.ed. Rio de Janeiro: Embrapa Solos, 2006. $306 \mathrm{p}$.

SAUBIDET, M.I.; FATTA, N.; BARNEIX, A.J. The effect of inoculation with Azospirillum brasilense on growth and nitrogen utilization by wheat plants. Plant and Soil, v.245, p.215-222, 2002 .

SHUKLA, S.K.; YADAV, R.L.; SUMAN, A.; SINGH, P.N. Improving rhizospheric environment and sugarcane ratoon yield through bioagents amended farm yard manure in udic ustochrept soil. Soil and Tillage Research, v.99, p.158-168, 2008.

SINGH, K.P.; SUMAN, A.; SINGH, P.N.; LAL, M. Yield and soil nutrient balance of sugarcane plant-ratoon system with conventional and organic nutrient management in subtropical India. Nutrient Cycling in Agroecosystems, v.79, p.209-219, 2007.

SUMAN, A.; SHASANY, A.K.; SINGH, M.; SHAHI, H.N.; GAUR, A.; KHANUJA, S.P.S. Molecular assessment of diversity among endophytic diazotrophs isolated from subtropical Indian sugarcane. World Journal of Microbiology and Biotechnology, v.17, p.39-45, 2001.

SUMAN, A.; SHRIVASTAVA, A.K.; GAUR, A.; SINGH, P.; SINGH, J.; YADAV, R.L. Nitrogen use efficiency of sugarcane in relation to its BNF potential and population of endophytic diazotrophs at different N levels. Plant Growth Regulation, v.54, p.1-11, 2008.

UNKOVICH, M.J.; HERRIDGE, D.; PEOPLES, M.B.; CADISCH, G.; BODDEY, B.; GILLER, K.; ALVES, B.; CHALK, $P$. Measuring plant-associated nitrogen fixation in agricultural systems. Canberra: Australian Centre for International Agricultural Research, 2008. 258p. (ACIAR. Monograph, 136).

URQUIAGA, S.; CRUZ, K.H.S.; BODDEY, R.M. Contribution of nitrogen fixation to sugar cane: nitrogen-15 and nitrogen balance estimates. Soil Science Society of America Journal, v.56, p.105-114, 1992.

URQUIAGA, S.; XAVIER, R.P.; MORAIS, R.F. de; BATISTA, R.B.; SCHULTZ, N.; LEITE, J.M.; SÁ, J. e M.; BARBOSA, K.P.; RESENDE, A.S. de; ALVES, B.J.R.; BODDEY, R.M. Evidence from field nitrogen balance and ${ }^{15} \mathrm{~N}$ natural abundance data of the contribution of biological $\mathrm{N}_{2}$ fixation to Brazilian sugarcane varieties. Plant and Soil, online first, 2011. Doi: 10.1007/ s11104-011-1016-3.

YADAV, R.L.; SUMAN, A.; PRASAD, S.R.; PRAKASH, O. Effect of Gluconacetobacter diazotrophicus and Trichoderma viride on soil health, yield and N-economy of sugarcane cultivation under subtropical climatic conditions of India. European Journal of Agronomy, v.30, p.296-303, 2009.

Recebido em 25 de agosto de 2011 e aprovado em 4 de janeiro de 2012 